\title{
Thermally Depolymerizable Polycarbonates V. Acid Catalyzed Thermolysis of Allylic and Benzylic Polycarbonates: A New Route to Resist Imaging ${ }^{a}$
}

\author{
Jean M. J. FréCHET, Francine BOUCHARD, Eva EICHLER, \\ Francis M. HouliHAN, ${ }^{\mathbf{b}}$ Takashi IIZAWA, ${ }^{\mathrm{c}}$ \\ Boguslaw KRYCZKA, ${ }^{\text {d }}$ and C. Grant WILLSON* \\ Department of Chemistry, University of Ottawa, \\ Ottawa, Ontario KIN 9B4 Canada \\ *IBM Almaden Research Center, 650 Harry Road, \\ San Jose, California 95120-6099, U.S.A.
}

(Received August 17, 1986)

\begin{abstract}
Polymers containing allylic and benzylic carbonate repeating units have been prepared by phase-transfer catalyzed polycondensation of activated bis-carbonates or carbamates and diols. The polymers are highly susceptible to thermal depolymerization and revert to small molecules when heated to temperatures which vary from 140 to $230^{\circ} \mathrm{C}$ depending on structure. The thermolysis temperatures are reduced to well below $100^{\circ} \mathrm{C}$ if catalytic amounts of acid are added to the polycarbonates. The thermolysis or acidolysis of bis allylic or benzylic carbonates provides a convenient route to aromatic compounds as demonstrated with both models and polymers. The polycarbonates can be used to formulate highly sensitive resist materials with potential for selfdevelopment of positive images. Some benzylic polycarbonates which produce polymerizable divinyl monomers upon thermolysis can be used to create negative images in a process which includes both depolymerization and photocrosslinking.

KEY WORDS Radiation-Sensitive / Polycarbonate / Resist / Chemical Amplification / Thermolysis / Phase-Transfer Catalysis / Thermoreversible / Polycondensation / Acidolysis /
\end{abstract}

Over the past decade, the development of resist materials with improved properties has proceeded at a noticeably faster pace as various laboratories strive to implement a variety of new conceptual designs. ${ }^{1}$ Of particular interest in the context of this report are efforts to develop polymers which possess high sensitivities and can be imaged in high quantum yield processess. Early examples of such systems include glycidyl methacrylate copolymers and similar materials containing pendant epoxide groups $^{2}$ which can be crosslinked in chain-wise fashion by exposure to radiation. However, a serious drawback to the use of these resists, and indeed of most materials which operate on the basis of ring-opening or vinyl polymerizations of pendant groups, is the existence of "dark reactions". . These are processes in which crosslinking continues even after irradiation has been completed, a phenomenon which can seriously impair resolution in some applications.

a Taken in part from the Ph. D. thesis of F. M. H. (University of Ottawa, 1984) and the M. Sc. thesis of F. B. (University of Ottawa, 1986). For parts III and IV see ref 7 and 14.

b Current address: AT\& T Bell Laboratories, Murray Hill, New Jersey, U.S.A.

c Current address: Department of Applied Chemistry, Kanagawa University, Yokohama.

d Current address: Department of Chemistry, University of Lodz, Poland. 


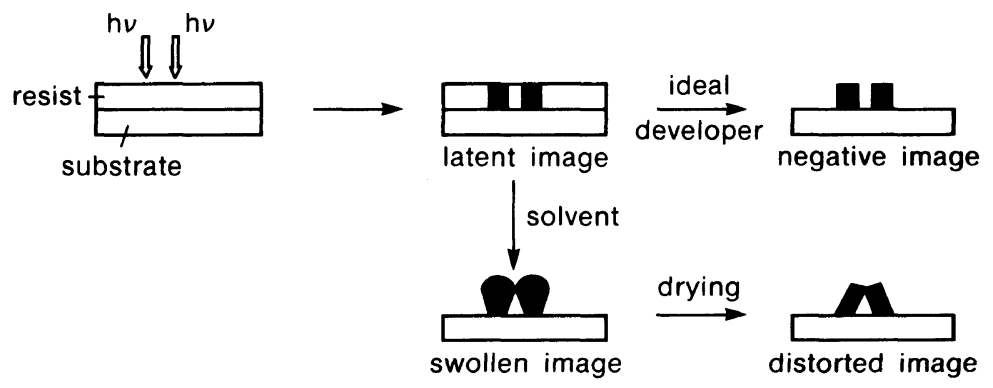

Figure 1. Image distortion due to solvent swelling of photocrosslinkable resists.

Another approach which also involves chain-like processes is based on polymers such as the halogenated and halomethylated ${ }^{4}$ polystyrenes. These resists operate via the radiation induced homolysis of a carbon-halogen bond, which generates radicals capable of rearrangements, recombination, or other reactions. Taken as a whole, these reactions lead to rapid network formation with insolubilization of the polymer in exposed areas.

Both of these types of resists produce negative-tone images due to radiation-induced crosslinking. Such materials, though extremely useful due to their high sensitivities and good processing characteristics, continue to suffer from the problem of swelling which effectively limits their resolution. Development of the resist images after irradiation is based on differential dissolution whereby the unexposed regions of the polymer film are dissolved away while the exposed regions, which have become crosslinked, remain on the substrate. The problem of swelling is due to the fact solvents which dissolve the uncrosslinked polymer also have a strong affinity for the crosslinked material which retains essentially the same chemical characteristics; solvation of the crosslinked film occurs readily and is accompanied by swelling and image distortion (Figure 1).

We have concentrated our efforts on a third approach $^{5}$ which avoids this problem of swelling, while maximizing the use of available photons through a process we term "chemical amplification." In these designs, chemical amplification is the result of photoinitiated chain or catalytic reactions where irradiation is used only to start a chain reaction or generate a catalyst in localized areas of a resist film. For example, a capped polyacetal such as poly(phthalaldehyde) can be used in combination with a radiation-sensitive substance which generates acid upon irradiation, to formulate a self-developing positive resist which operates on the basis of a ceiling temperature phenomenon. ${ }^{5,6}$ The acid which is photogenerated within exposed areas of the polymer catalyzes the thermal reversion of the polyacetal to monomeric phthalaldehyde which results in the appearance of an image. While such room-temperature spontaneous development of images could appear quite attractive, it may be advantageous to incorporate a certain activation energy ${ }^{7}$ in the development process to avoid the spontaneous release of volatile moieties which might contaminate the exposure instrument.

This report describes a family of allylic and benzylic polycarbonates which can be used to formulate resist materials operating on the basis of catalyzed thermolysis of polymer chains.

\section{RESULTS AND DISCUSSION}

We have recently described ${ }^{8,9}$ the preparation of some new thermally depolymerizable polycarbonates based on tertiary diols such as 


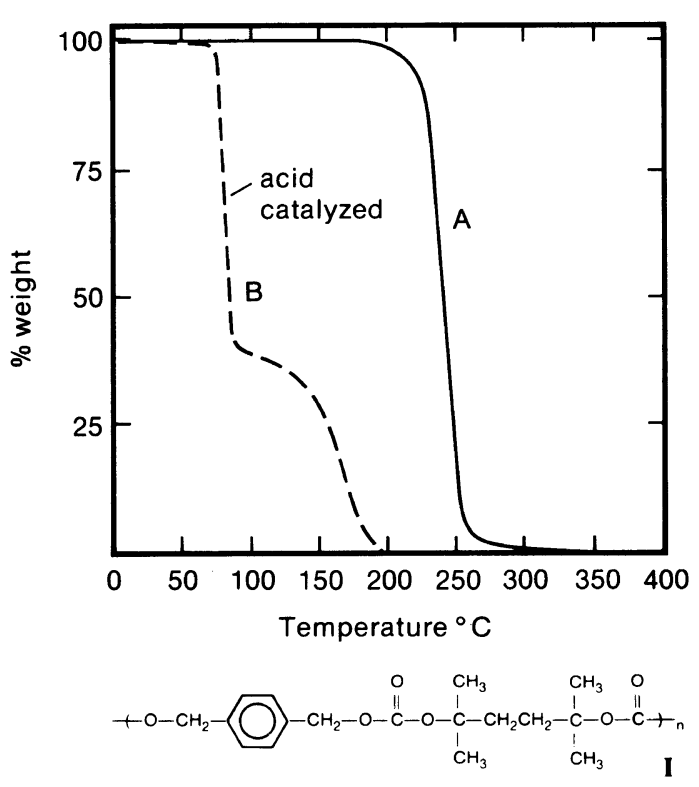

Figure 2. Thermogravimetric analysis of polycarbonate I (A) normal TGA trace (B) TGA trace for polymer containing a trace of acid.

2,5-dimethyl-2,5-hexanediol. These polycarbonates undergo rapid thermal depolymerization with evolution of volatile small molecules when heated to a certain threshold temperature. This thermal depolymerization is not the manifestation of a ceiling temperature phenomenon but is the result of multiple synchronous elimination reactions which are facilitated by the presence of tertiary carbonate units in the polymer.

\section{Acidolysis of Tertiary Copolycarbonates}

The proposed mechanism ${ }^{10}$ for the thermolysis of esters and carbonates is an $E_{\mathrm{i}}$ elimination. In agreement with previous suggestions, we believe that in the case of tertiary carbonates at least, the intermediates involved in the thermolysis reaction possess considerable carbocationic character. Indeed, as can be seen in Figure 2, the thermolysis temperature is lowered considerably when a catalytic amount of acid is added to tertiary copolycarbonate I. In this instance, polymer I which normally decomposes near $200^{\circ} \mathrm{C}$ (thermogra- vimetric trace A, Figure 2) sees its threshold decomposition temperature lowered to well below $100^{\circ}$ (thermogravimetric trace B) in the presence of a small amount of acid. The irregular shape of TGA trace B in Figure 2 is due to the relative lack of volatility of the $p$ benzenedimethanol which is liberated in the depolymerization process. With polymer I, the thermolysis and acid-catalyzed thermolysis (acidolysis) reactions essentially lead to the same product mixture. Therefore, the thermal behavior of such polycarbonates, which can be monitored conveniently by thermolysis-gas chromatography-mass spectrometry, is a useful predictor of their acidolytic behavior. Figure 3 shows the chromatogram which is obtained when polymer I is heated above its threshold decomposition temperature. All of the expected olefinic and hydroxylated products are observed, including a C6 fragment containing both alcohol and alkene functionalities which arises from tertiary diol units located at chain ends.

\section{Principles of Imaging by Depolymerization}

The difference in thermolysis temperatures between the normal and acid-catalyzed depolymerization processes can be exploited to design a highly sensitive imaging system $^{7}$ (Figure 4). The photosensitive layer consists of a thin film of a copolycarbonate such as I containing a small amount of a radiationsensitive triphenylsulfonium or triphenyliodonium salt. ${ }^{11}$ Imagewise exposure of the polymer film with radiation of appropriate wavelength causes decomposition of the onium salt with the liberation of catalytic amounts of strong acid within the polycarbonate. As exposure is carried out at room temperature, this only creates a latent image as the acid does not react with the polymer at an appreciable rate in the solid-state. Development of the image is then accomplished by simply heating the exposed film to $60-80^{\circ}$ which causes the acid-catalyzed thermolysis to occur very rapidly in the exposed 


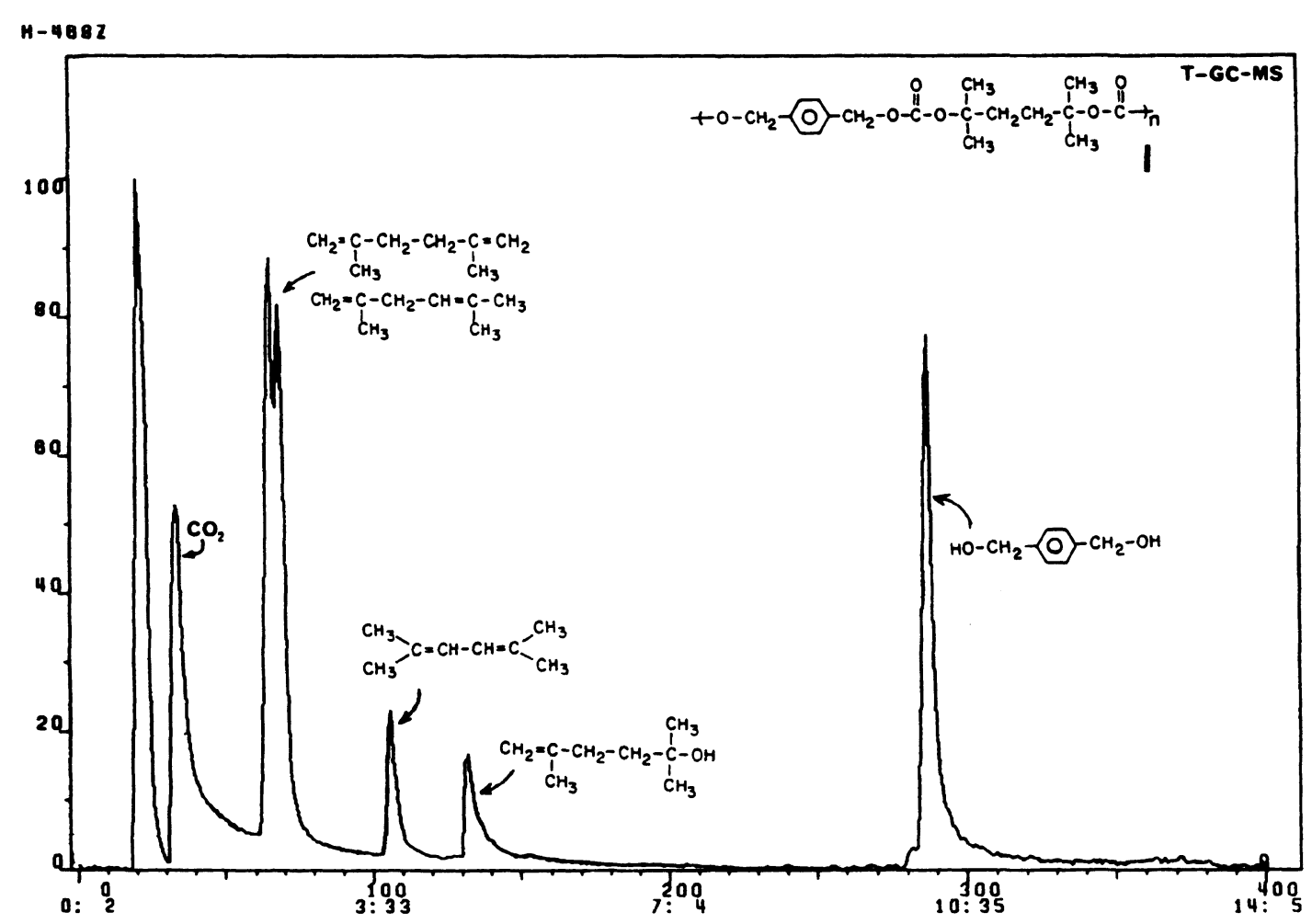

Figure 3. Gas chromatographic (GC-MS) analysis of the thermolysis products of polycarbonate I.

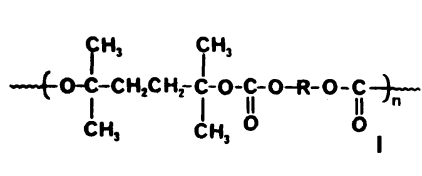

$\mathrm{Ph}_{\mathbf{g}} \mathrm{S}^{\oplus} \mathrm{AsF}_{\mathrm{q}}^{\ominus}$
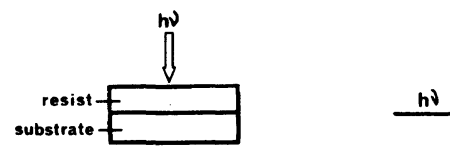

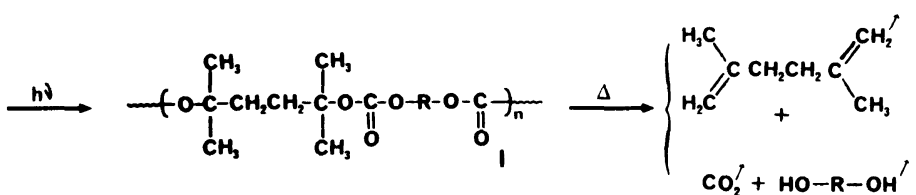

$H^{\oplus}$ etc.
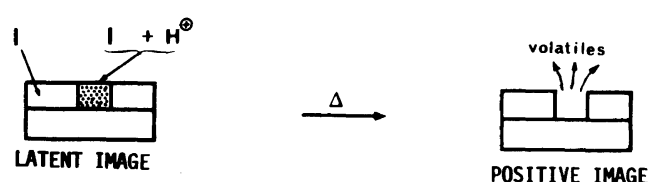

Figure 4. Imaging of a thermally depolymerizable polycarbonate resist system.

areas of the film only. This leads to the appearance of a positive-tone image as volatile material is evolved. It should be noted here that the acid produced by exposure to light is used as a catalyst and is not consumed stoichiometrically in the depolymerization process. It is this property which leads to chemical amplification as each photochemically produced molecule of acid can cleave a large number of carbonate bonds before being eventually destroyed in an occasional terminating side-reaction. 


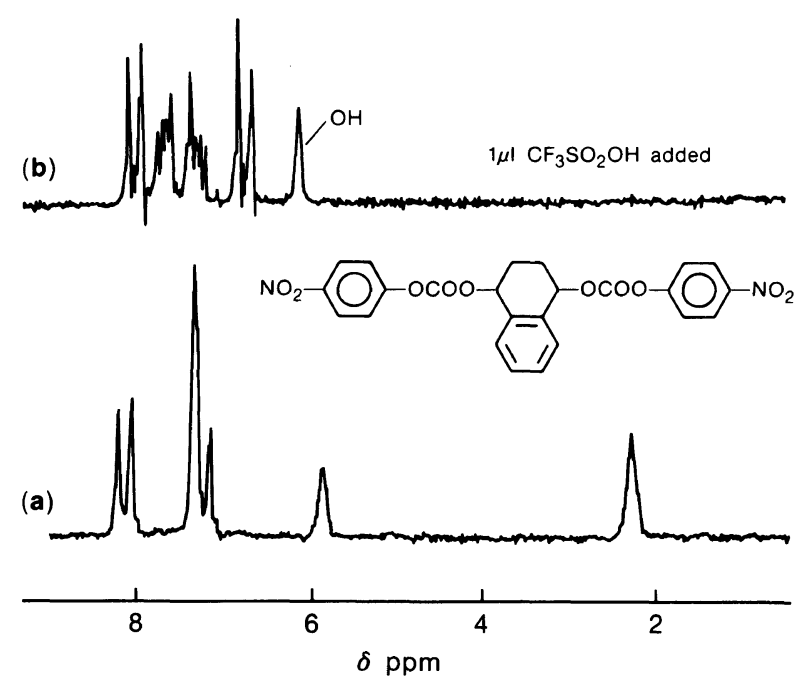

Figure 5. $60 \mathrm{MHz}{ }^{1} \mathrm{H}$ NMR spectrum of 1,4-(p-nitrophenyloxycarbonyl)-1,4-dihydroxy-1,2,3,4-tetrahydronaphtalene. (a) normal spectrum; (b) spectrum of acid-catalyzed decomposition products.

\section{Extension of the Design: Model Studies}

Simple consideration of the mechanism of acidolysis of tertiary carbonates ${ }^{7,12}$ led us to speculate that structures containing appropriate benzylic and allylic carbonate groups should undergo a similar low temperature acidolytic cleavage. Indeed, both 2-cyclohexenyl phenyl carbonate and phenyl 1-phenylethyl carbonate undergo facile thermolysis and acidolysis with liberation of phenol, carbon dioxide and 1,3-cyclohexadiene or styrene. This finding may be applied to the design of polycarbonates using appropriate bis-allylic or bis-benzylic diols such as 2-cyclohexen1,4-diol or 1,4-bis(1-hydroxyethyl, benzene). Carbonates derived from these alcohols should undergo facile acidolysis and thermolysis with formation of benzene or 1,4-divinylbenzene respectively. This expectation was confirmed by the study of a variety of bifunctional models including for example the bis- $p$ nitrophenyl carbonate derivatives of 2cyclohexen-1,4-diol or of 1,4-dihydroxy1,2,3,4-tetrahydronaphthalene. Figure 5a shows the $60 \mathrm{MHz}{ }^{1} \mathrm{H}$ NMR spectrum of one such bis-carbonate $\left(40 \mathrm{mg}\right.$ in $\left.0.5 \mathrm{ml} \mathrm{CDCl}_{3}\right)$. Upon treatment of this solution with $1 \mu \mathrm{l}$ trifluoromethane sulfonic acid at room temperature, carbon dioxide is evolved immediately. A ${ }^{1} \mathrm{H}$ NMR spectrum recorded after 10 minutes (Figure 5b) shows no starting carbonate remaining while both naphthalene and $p$-nitrophenol have been liberated quantitatively. Similar results are obtained with other model compounds though care must be taken to design the molecules in such a way that sidereactions such as alkylations are avoided.

As can be seen in Figure 5, this facile elimination of allylic and benzylic carbonates also provides an excellent and high yield route to aromatization, a finding which can be applied in other areas of polymer chemistry such as the preparation of conducting polymers.

\section{Preparation of the Polycarbonates}

The target structures for this study were copolycarbonates containing appropriate combinations of diols with structures IIaVIIIa (Figure 6). Though several routes are possible depending on the exact structures which are required, it was desirable to develop a general procedure which could be used in the preparation of any type of copolycarbonate including those of sterically hindered diols. 


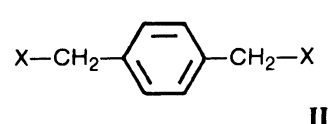

II
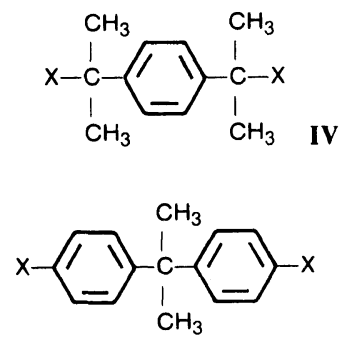

VI

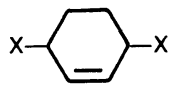

VIII

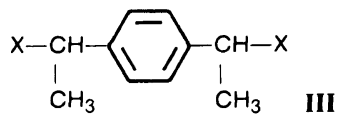

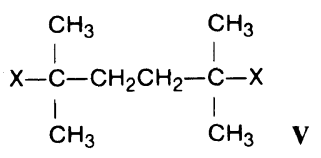

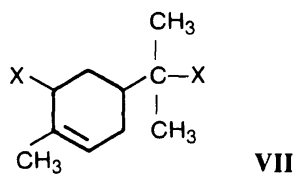

(a) $\mathrm{X}=\mathrm{OH}$

(b)<smiles>[X]OC(=O)n1ccnc1</smiles><smiles>[X]OC(=O)Oc1ccc([N+](=O)[O-])cc1</smiles>

Figure 6. Structures of the monomers used in the preparation of polycarbonates.

Our recent report ${ }^{8.9}$ on the synthesis of copolycarbonates containing tertiary diol structures was based upon the polycondensation of $\mathrm{Ci}-\mathrm{N}$-acylimidazole derivatives of dicarboxylic acids with appropriate diols under phasetransfer catalysis. Another group ${ }^{13}$ has claimed success in the preparation of similar tertiary copolycarbonates through the condensation of the bischloroformate of $4,4^{\prime}$-isopropylidene-diphenol with tertiary diols such as 2,5-dimethyl-2,5-hexanediol. The product of this reaction is reported to have both a high glass transition temperature and a high melting point $\left(140\right.$ and $340^{\circ} \mathrm{C}$, respectively). These findings are extremely surprising in view of our own data ${ }^{7-9}$ on this and similar tertiary copolycarbonates $\left(T_{\mathrm{g}}\right.$ usually below $80^{\circ} \mathrm{C}$ and $T_{\mathrm{m}}$ below $150^{\circ} \mathrm{C}$ ). Most surprising perhaps is the claim ${ }^{15}$ to high stability (over $480^{\circ} \mathrm{C}$ ) while all of our tertiary polycarbonates, including that with an identical structure, ${ }^{7}$ decompose near $200^{\circ} \mathrm{C}$, a finding which is in keeping with the well-known thermal lability of tertiary esters, carbamates, carbonates and chloroformates. In our hands, the use of the bischloroformate of 4,4'-isopropylidene diphenol in condensations with tertiary diols led to products which contain almost exclusively bisphenol A carbonate units.

Though bischloroformates may indeed be quite suitable in reactions with less hindered reactive diols such as IIIa or VIIIa, a more suitable route was sought for the more difficult syntheses. Polycondensation reactions involving $\mathrm{N}$-acylimidazoles are only possible with aliphatic diols: diphenols cannot be used due to the relative basicities of the phenolate and imidazole anions. This problem can be remedied by replacing the imidazole anion with a better leaving group such as the anion of $p$ nitrophenol, trichlorophenol or $N$-hydroxysuccinimide. Though several of these have been tested successfully, only polymers obtained from $p$-nitrophenyl carbonates (Structures IIIc-VIIIc) or the $N$-acylimidazoles (Structures IIIb-VIIIb) will be described in this report.

The polycondensation reactions were carried out using an exact stoichiometric balance of the diol and activated carbonate or car- 
Thermally Depolymerizable Polycarbonates V.

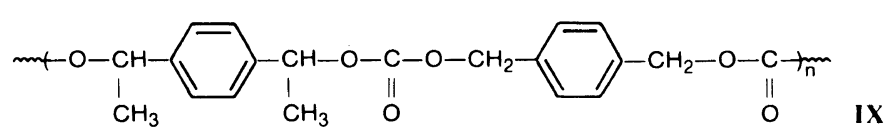

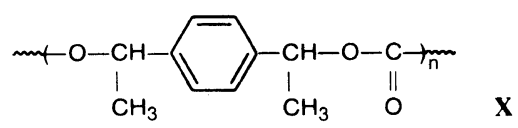

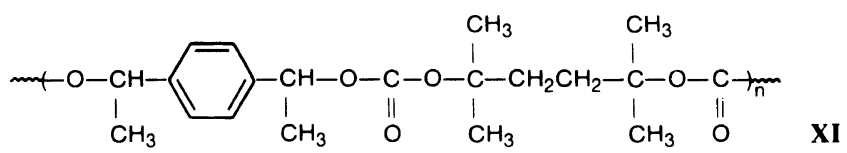

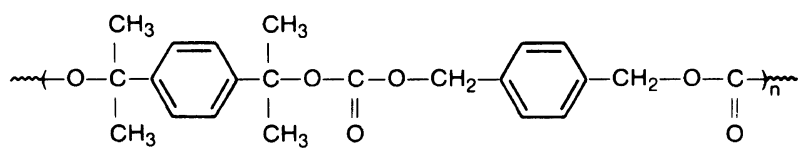

XII

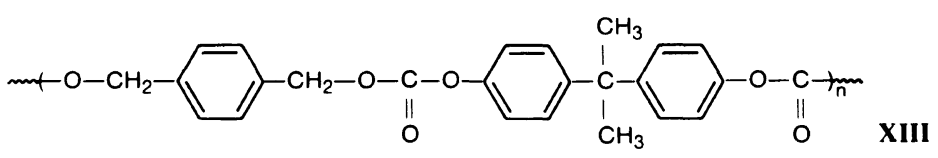

Figure 7. Structures of benzylic polycarbonates.<smiles>CC(C)OC1C=CC(OC(=O)O[Tl])CC1</smiles>

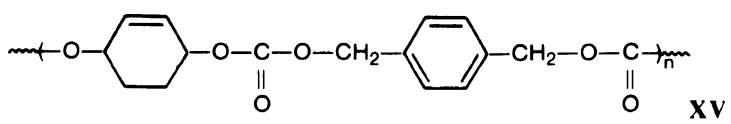

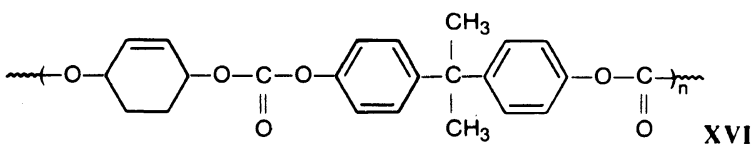

>

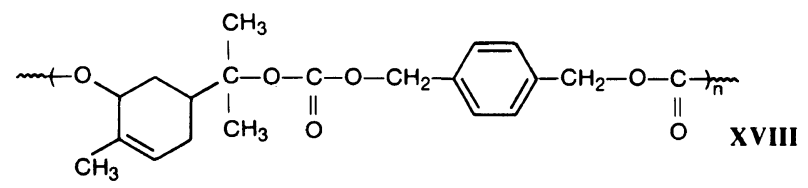

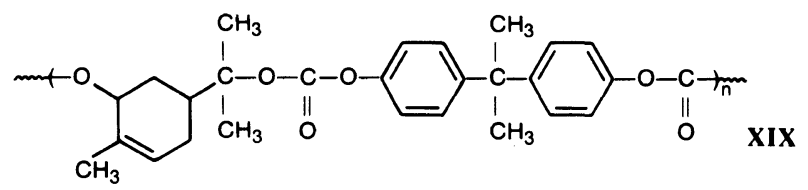

Figure 8. Structures of allylic polycarbonates. 
Table I. Polymers containing benzylic carbonate groups

\begin{tabular}{|c|c|c|c|c|c|c|c|c|c|c|}
\hline Polymers & $\begin{array}{l}\text { Activated } \\
\text { monomer }^{\mathrm{a}}\end{array}$ & $\begin{array}{c}\text { Diol } \\
\text { structure }^{\mathrm{a}}\end{array}$ & $\begin{array}{l}\text { Reaction } \\
\text { time } / \mathrm{h}\end{array}$ & Yield $/ \%$ & $\begin{array}{l}\bar{M}_{n} \times 10^{-3} \\
\text { Osmom. }^{\mathrm{b}}\end{array}$ & $\begin{array}{c}\bar{M}_{n} \times 10^{-3} \\
\mathrm{GPC}^{\mathrm{c}}\end{array}$ & $\begin{array}{c}\bar{M}_{w} \times 10^{-3} \\
\mathrm{GPC}^{\mathrm{c}}\end{array}$ & $\bar{M}_{w} / \bar{M}_{n}$ & $\frac{T_{\mathrm{g}}}{{ }^{\circ} \mathrm{C}}$ & $\frac{T_{\mathrm{dec}}{ }^{\mathrm{d}}}{{ }^{\circ} \mathrm{C}}$ \\
\hline IX & IIb & IIIa & 48 & 87 & 14.7 & - & - & - & 60 & 214 \\
\hline $\mathrm{X}$ & IIIb & IIIa & 19 & 73 & 7.5 & 2.7 & 13.7 & 5.1 & 78 & 230 \\
\hline$X$ & IIIb & IIIa & 48 & 86 & 12.5 & 6.8 & 12.9 & 1.9 & 80 & 230 \\
\hline XI & $\mathrm{Vb}$ & IIIa & 12 & 71 & 10.3 & 17.8 & 30.7 & 1.7 & 58 & 190 \\
\hline XII & $\mathrm{IVb}$ & IIa & 24 & 80 & 14.0 & 2.5 & 6.1 & 2.5 & 46 & 140 \\
\hline XIII & IIc & VIa & 24 & 91 & 18.2 & - & - & - & 90 & 260 \\
\hline
\end{tabular}

Table II. Polymers containing allylic carbonate groups

\begin{tabular}{|c|c|c|c|c|c|c|c|c|c|c|}
\hline Polymers & $\begin{array}{l}\text { Activated } \\
\text { monomer }^{\mathrm{a}}\end{array}$ & $\begin{array}{c}\text { Diol } \\
\text { structure }^{a}\end{array}$ & $\begin{array}{c}\text { Reaction } \\
\text { time/h }\end{array}$ & Yield $/ \%$ & $\begin{array}{l}\bar{M}_{n} \times 10^{-3} \\
\text { Osmom. }^{\mathrm{b}}\end{array}$ & $\begin{array}{c}\bar{M}_{n} \times 10^{-3} \\
\mathrm{GPC}^{\mathrm{c}}\end{array}$ & $\begin{array}{c}\bar{M}_{w} \times 10^{-3} \\
\mathrm{GPC}^{\mathrm{c}}\end{array}$ & $\bar{M}_{w} / \bar{M}_{n}$ & $\frac{T_{\mathrm{g}}}{{ }^{\circ} \mathrm{C}}$ & $\frac{T_{\mathrm{dec}}{ }^{\mathrm{d}}}{{ }^{\circ} \mathrm{C}}$ \\
\hline XIV & VIIIc & VIIIa & 24 & 76 & - & - & - & - & - & - \\
\hline$X V$ & $\mathrm{IIb}$ & VIIIa & 45 & 56 & 6.0 & 2.8 & 3.9 & 1.4 & - & 200 \\
\hline$X V$ & IIc & VIIIa & 90 & 91 & 17.6 & 7.9 & 15.0 & 1.9 & 65 & 200 \\
\hline XVI & VIIIc & VIa & 72 & 90 & 13.9 & 20.6 & 40.3 & 2.0 & 144 & 215 \\
\hline XVI & VIIIc & VIa & 72 & 92 & 17.1 & - & - & - & 146 & 215 \\
\hline XVII & VIIc & VIIa & 24 & $42^{\mathrm{e}}$ & - & - & - & - & - & - \\
\hline XVIII & VIIb & IIa & 24 & 75 & - & 0.85 & 1.7 & 2.0 & - & 一 \\
\hline XVIII & VIIc & IIa & 41 & 80 & 11.1 & 6.1 & 10.0 & 1.6 & 111 & 185 \\
\hline XIX & VIIc & VIa & 48 & 79 & 15.4 & 15.3 & 32.2 & 2.1 & 130 & 180 \\
\hline XIX & VIIc & VIa & 56 & 93 & 23.5 & - & - & - & 132 & 180 \\
\hline
\end{tabular}

a See figures for monomer structures.

b Number average molecular weight by osmometry in toluene or 1,2-dichloroethane.

c Gel permeation chromatography in THF using polystyrene for calibration.

d Decomposition temperature taken at point where $c a$. $5 \%$ mass is lost.

e Oligomeric material.

bamate under solid-liquid phase transfer conditions with solid anhydrous potassium carbonate and 18-crown-6 at room temperature. This procedure was used to prepare polymers IX-XIX (Figures 7 and 8); results of these syntheses are given in Tables I and II. In the case of condensations involving $\mathrm{N}$-acylimidazoles, the polymerization could also be performed using a small amount of sodium metal instead of phase transfer catalysis but this procedure generally led to lower molecular weight polymers or even oligomers.
Benzylic Polycarbonates and Their Thermolysis The thermolysis of the polycarbonates containing active benzylic moieties is most readily monitored by thermogravimetric (TGA) as well as GC-MS analysis. Standard TGA studies are useful as they provide information on the threshold temperature for the decomposition of the polymers as listed in Table I.

It is particularly interesting to contrast the thermolytic behavior of polymer IX, X, and $\mathrm{XI}$ which all contain active carbonate units derived from 1,1'-(1,4-phenylene)diethanol. 


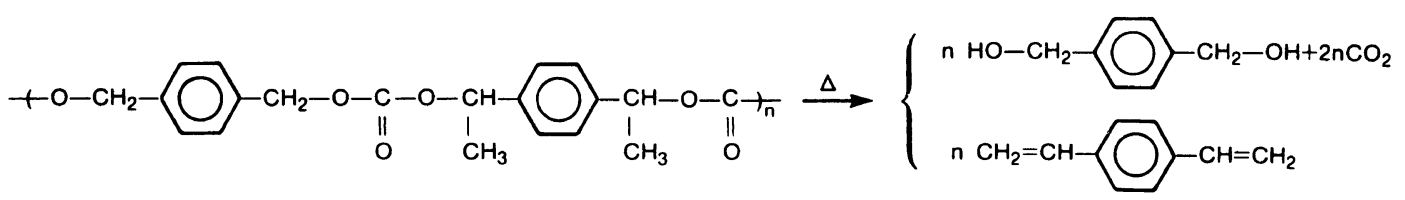

IX
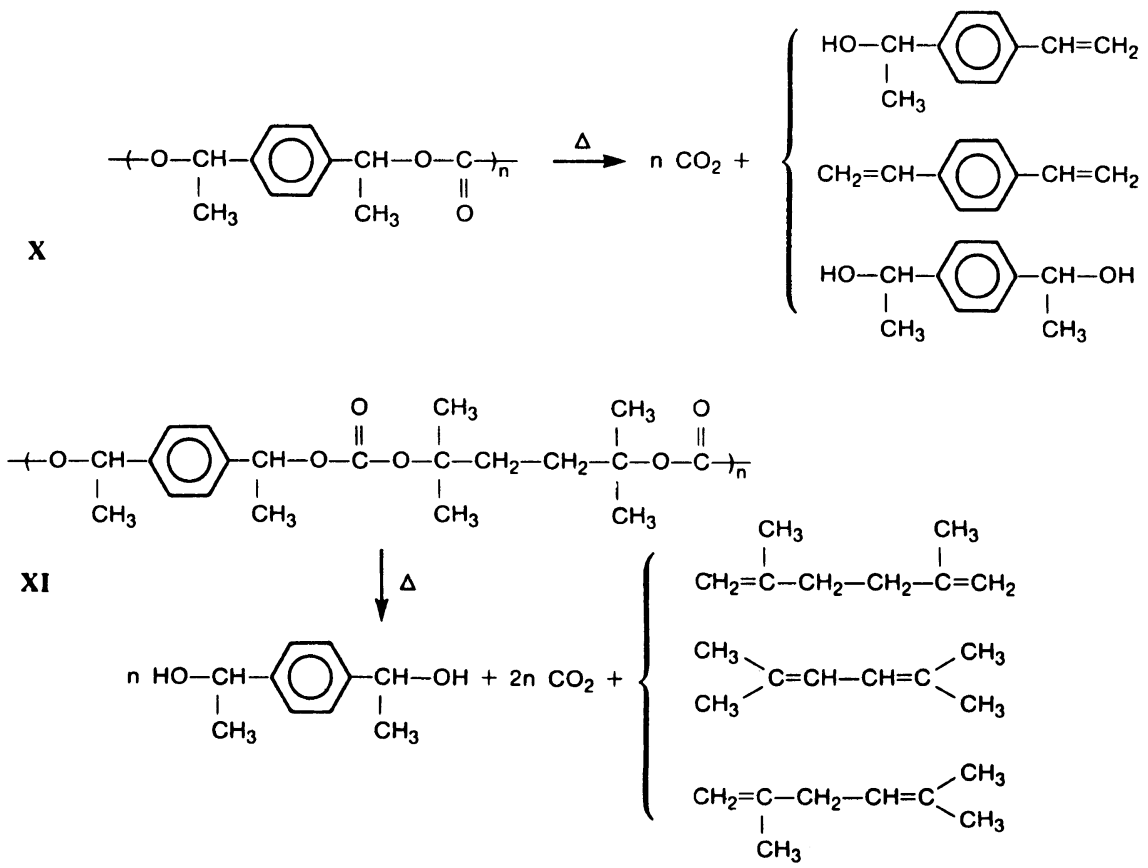

Figure 9. Thermolysis of benzylic polycarbonates IX, X, XI.

As can be seen in Table I, polymer XI has the lowest threshold thermolysis temperature of this series: ca. $190^{\circ} v s$. over $210^{\circ} \mathrm{C}$ for IX and $\mathrm{X}$. Indeed the decomposition temperature of $\mathrm{XI}$ is almost identical to that for polymer I which contains only tertiary carbonate groups as labile linkages. As the thermolysis temperature reflects the stability of the intermediate involved in the reaction this finding suggest that it is the tertiary groups and not the secondary benzylic carbonate groups which are the "active" units in XI. This is readily confirmed by the results of thermolysis GCMS studies on polymers IX, X, and XI. All three thermolysis reactions are extremely clean and result in the formation of the expected diene and diol products in addition to $\mathrm{CO}_{2}$ (Figure 9). Thus IX decomposes near $214^{\circ} \mathrm{C}$ with evolution of $p$-divinylbenzene and $p$ benzenedimethanol. Structure $\mathrm{X}$ decomposition of which must lead to both alkene and alcohol units thermolyses at a higher temperature $\left(c a .230^{\circ} \mathrm{C}\right)$ with formation of all three possible products including the nonsymmetrical $p$-(1-hydroxyethyl)styrene as the major product (Figure 10). Polymer XI decomposes to form all three possible dienes derived from the tertiary diol and 1,1'-(1,4phenylene)diethanol, no divinylbenzene or other styrenic products were detected.

Polymer XII is even more sensitive to thermolysis than XI and decomposes near $140^{\circ} \mathrm{C}$. This very low decomposition temperature is likely due to the fact its active units are both tertiary and benzylic. In contrast polymer XIII which contains no "active" carbonate units 


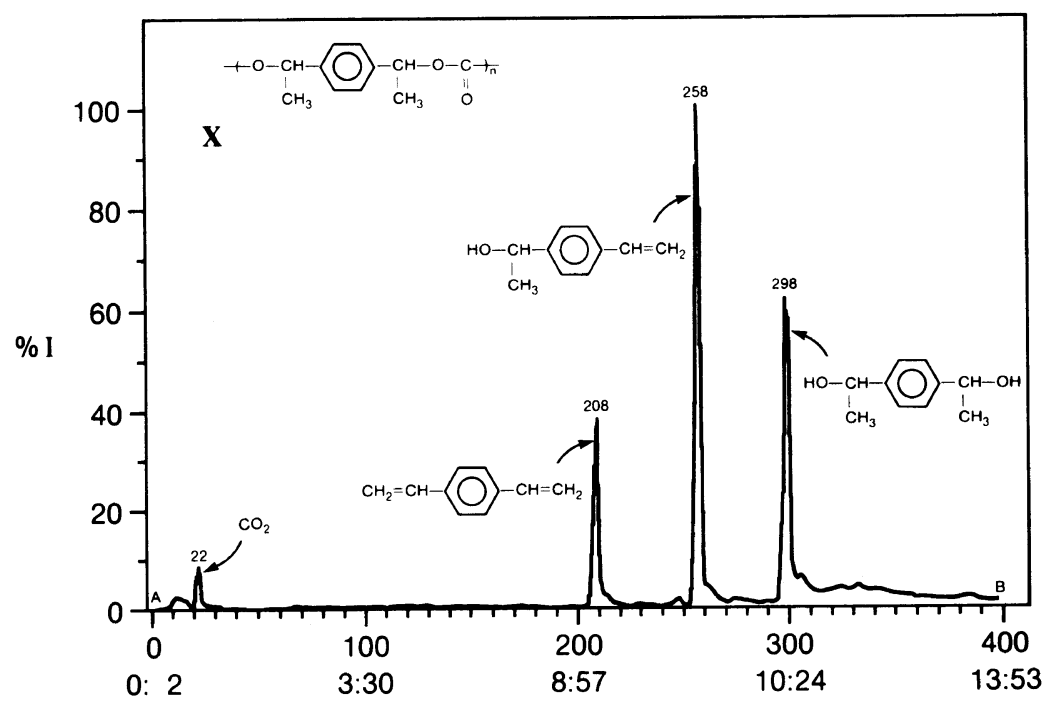

Figure 10. Gas chromatographic (GC-MS) analysis of the thermolysis products of benzylic polycarbonate X.

only starts to decompose slowly above $260^{\circ} \mathrm{C}$ and is only approximately $50 \%$ decomposed at $400^{\circ} \mathrm{C}$. Monitoring of the thermolysis of XIII by GC-MS reveals that $4,4^{\prime}$-isopropylidenediphenol is liberated while no free $p$ benzenedimethanol is observed as the depolymerization mechanism which must be operative in this case is different from that for IXXII due to the lack of the alpha hydrogens which are needed in the elimination process. Similarly, the homopolycarbonate of $p$ benzenedimethanol requires temperatures in excess of $300^{\circ} \mathrm{C}$ to initiate a thermolysis process in which no free $p$-benzenedimethanol appears to be produced. The very high reactivity of polymer XII is also apparent in thermolysis experiments where polymer XII reacts more rapidly than any other benzylic or tertiary polycarbonate.

\section{Allylic Polycarbonates and Their Thermolysis}

The allylic diol of choice for incorporation into a depolymerizable polycarbonate may be 2-cyclohexen-1,4-diol. Polycarbonates containing this diol should depolymerize to form benzene as was observed in the model studies. Polymer XV thermolyses rapidly near $200^{\circ} \mathrm{C}$ though TGA analysis shows that a small re- sidue may remain at $300^{\circ} \mathrm{C}$ depending on the conditions used for the thermogravimetric analysis. A GC-MS study conducted in the absence of oxygen shows that $p$-benzenedimethanol, benzene, and carbon dioxide are the major volatile products of the thermal decomposition of XV (Figure 11). In addition, a small amount of 2,4-cyclohexadien-1-ol and yet smaller amounts of 2-cyclohexen-1one, 3-cyclohexen-1-one and 2,5-cyclohexadien-1-ol are detected. These products originate from the end groups of the polymer.

Polymer XVI which contains 4,4'-isopropylidene-diphenol in addition to the active 2-cyclohexen-1,4-diol units thermolyses at the slightly higher temperature of $215^{\circ} \mathrm{C}$. Here again the thermolysis curve is not as ideal as in the case of polymers I or XI and after the rapid loss of $80 \%$ of total mass, more elevated temperatures are required to complete the thermolysis process. A GC-MS study ${ }^{14}$ of the thermolysis reaction shows benzene, carbon dioxide and bisphenol $\mathrm{A}$ as the sole volatile products of the thermal breakdown of polymer XVI suggesting that, in this instance, 4,4'isopropylidene-diphenol moieties were located at the chain ends. Another diol of great interest in the context of this study is $p$-menth-6- 
Thermally Depolymerizable Polycarbonates V.

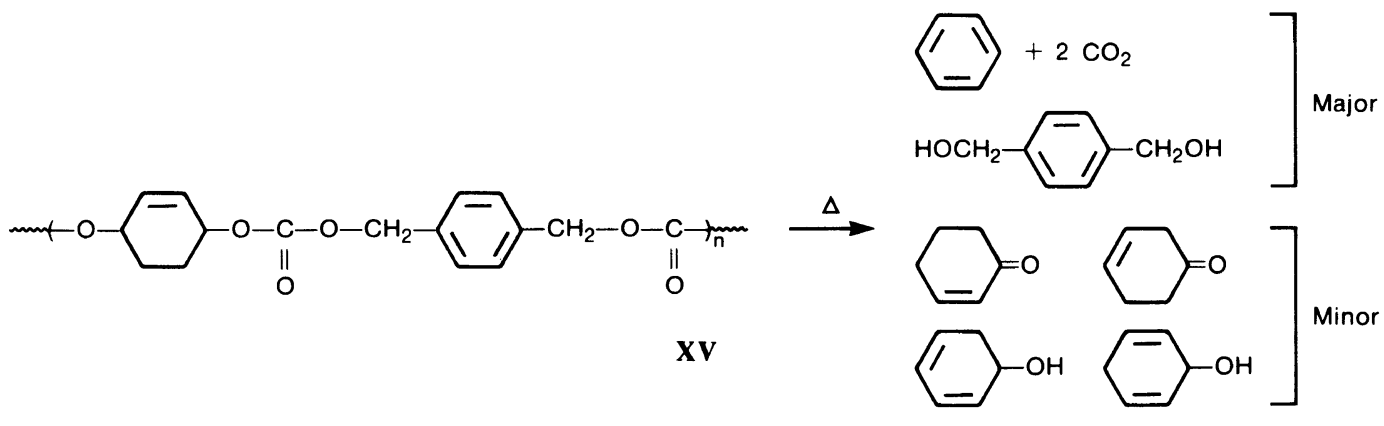

Figure 11. Thermolysis of allylic polycarbonate XV.

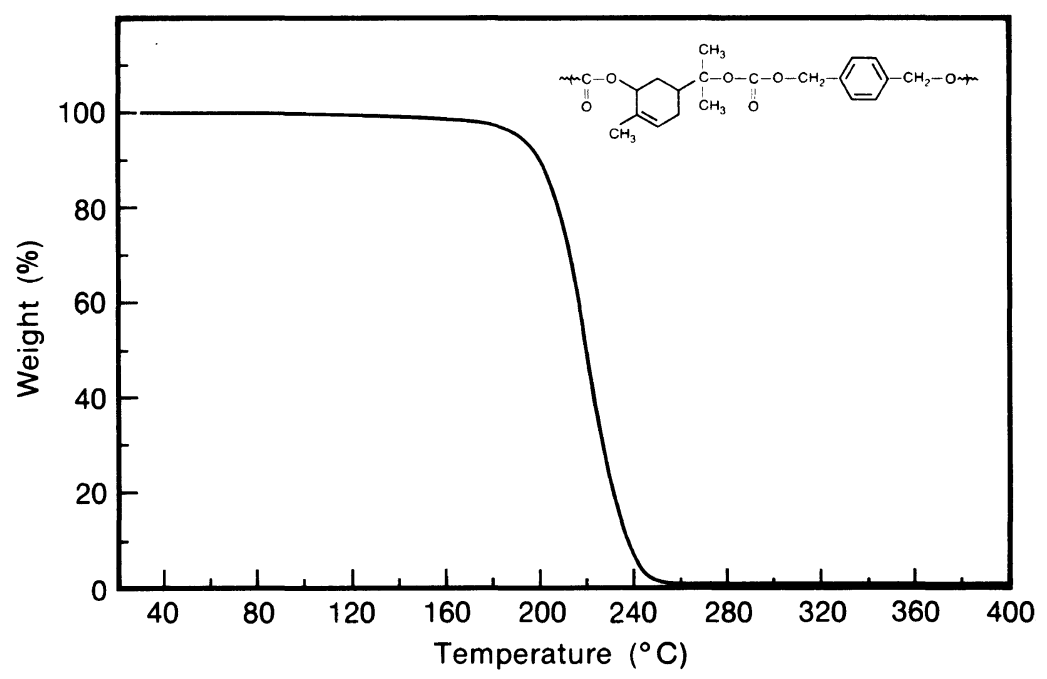

Figure 12. Thermogravimetric analysis of polymer XVIII.

ene-2,8-diol also known as sobrerol. This terpene diol contains both an allylic and tertiary hydroxyl, each of which can be used to create a thermally labile carbonate bond. Both polycarbonates XVIII and XIX undergo thermolysis at the relatively low temperatures of 185 and $180^{\circ} \mathrm{C}$, respectively. However, while the decomposition of polymer XVIII is near ideal (Figure 12), polymer XIX does not decompose as smoothly and approximately $10 \%$ of the polymer's starting mass still remains at $300^{\circ} \mathrm{C}$. GC-MS analysis of the volatile products resulting from the decomposition of XVIII under inert atmosphere shows the formation of the expected $p$-benzenedimethanol, 2-methyl-5-isopropylidene-1,3-cyclohexadiene and 2-methyl-5-isopropenyl-1,3-cyclohexa- diene which isomerizes partially to $p$-cymene. ${ }^{18}$

Small amounts of other decomposition products were also detected. These included chain-end fragments and dimeric ether units derived from $p$-benzenedimethanol and a dienic derivative of $p$-menth-6-ene-2,8-diol. The presence of such ether fragments suggests that, under thermolysis, extrusion of $\mathrm{CO}_{2}$ may proceed via a polar transition state of high carbocationic character which would favor ether formation. This suggestion is also supported by other studies with carbonate and ether model compounds. ${ }^{19}$ Finally the thermolysis of XIX monitored by GC-MS analysis afforded the results shown in Figure 13. All the expected decomposition products (Figure 14) are obtained but no ether fragments are found 


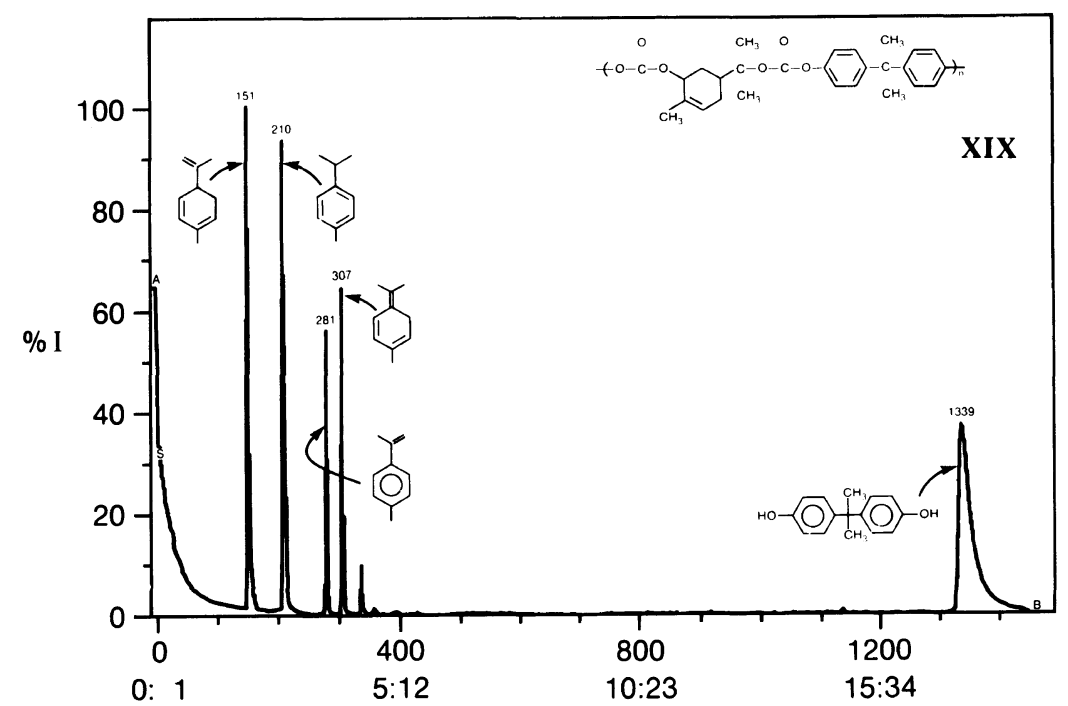

Figure 13. Gas chromatograph (GC-MS) analysis of the thermolysis products of polycarbonate XIX.

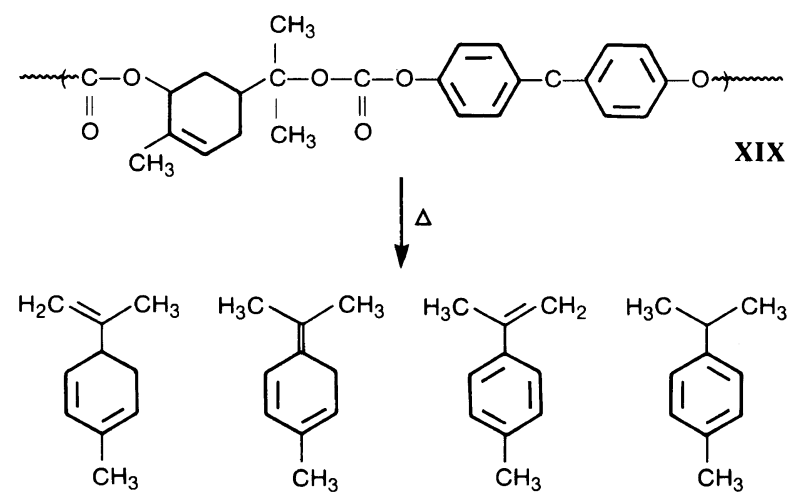<smiles>CC(C)(c1ccc(O)cc1)c1ccc(O)cc1</smiles>

Figure 14. Thermolysis of polycarbonate XIX.

in this case. The small amount of 4-methyl- $\alpha$ methylstyrene which is detected originates from a chain-end fragment which is oxidized and dehydrated.

\section{Imaging Experiments}

Imaging experiments we carried out on films of the various polycarbonates using the technique described in Figure 4. Most experiments were performed using triphenylsulfonium hexa- fluoroantimonate as the radiation-sensitive acid precursor. As expected, irradiation to UV light at $254 \mathrm{~nm}$ resulted in the liberation of acid with the creation of a latent image only. A visible image develops immediately upon heating the exposed polymer film to $55-80^{\circ} \mathrm{C}$. In view of the generally low volatility of the diols which are liberated in this acid-catalyzed depolymerization process, full development was not possible at such low temperatures and at 

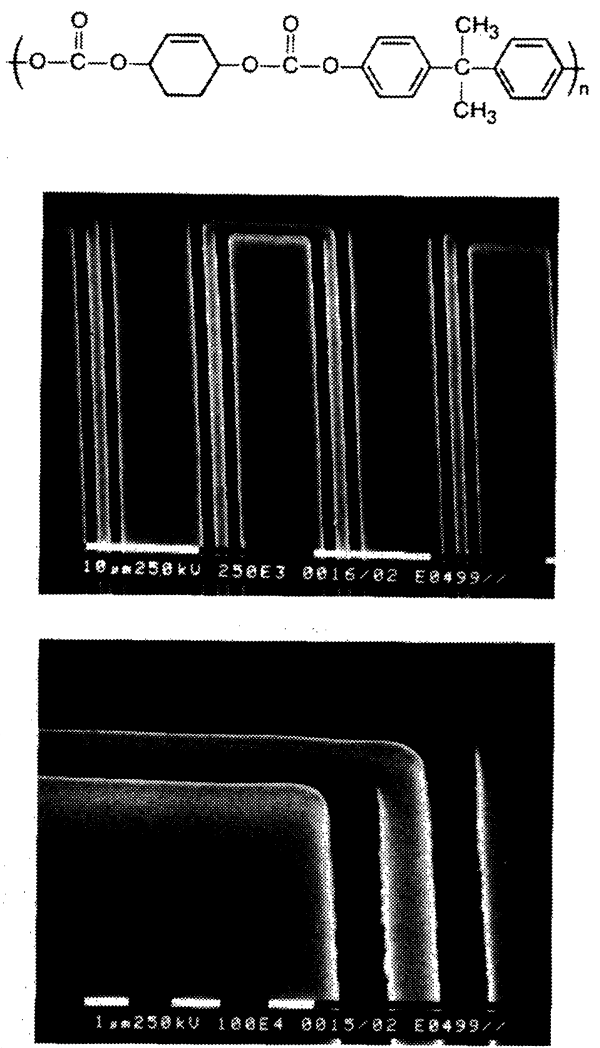

Figure 15. Imaging of polymer XVI.

atmospheric pressure. As the exposed polymer films should not be heated much beyond their $T_{\mathrm{g}}$ - any flow of polymer would result in image distortion - dry development should only be achievable in vacuo. An alternate wet development process takes advantage of the great polarity and solubility difference between the liberated diol and the unexposed polymer. Washing the partly developed images with 2propanol or similar polar solvents results in full image development as shown in Figures 15 and 16 . These images were obtained by casting a $c a .1 \mu \mathrm{m}$ thick of polycarbonates containing a few percent of the photoactive salt onto $125 \mathrm{~mm}$ silicon wafers which were exposed through a mask using a Perkin-Elmer 500 projection printing tool. After image development the silicon wafer is split along its crystal axis to allow for an examination of the image<smiles>CC1=CCC(C(C)(C)OC(=O)Oc2ccc(C(C)(C)c3ccccc3)cc2)CC1OC(=O)OC(C)(C)C</smiles>

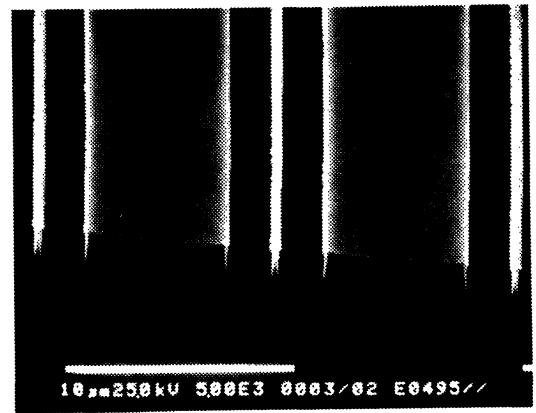

Figure 16. Imaging of polymer XIX.

profile by electron microscopy. The image shown in Figure 15 was obtained using polymer XVI while the image shown on Figure 16 was obtained from XIX. Good quality positive images were also obtained with other tertiary or allylic polycarbonates. In contrast both polymers IX and XII could be used to produce negative image as the bifunctional styrenic products of the acidolysis polymerized readily by cationic processes. In this case, however, the images were of lower quality as film thickness was greatly reduced due to the loss of volatile diols from the exposed areas.

\section{EXPERIMENTAL}

All diols used in this study were obtained from commercial sources with the exception of 2-cyclohexen-1,4-diol and 1,1'-(1,4phenylene)-diethanol which were prepared from cyclohexene and 1,4-diacetyl-benzene respectively. Thermogravimetric and Differential Scanning Calorimetry experiments were performed on Mettler instruments while GC-MS analyses were carried out on a VG$7070 \mathrm{E}$ double focusing mass spectrometer used as detector on a gas chromatograph fitted with $30 \mathrm{~m}$ capillary columns. Molecular weight measurements were done on a Wescan Model 
231 membrane osmometer. GPC analyses were performed by comparison to polystyrene standards on a Waters model 150 gel permeation chromatograph equipped with five microstyragel columns with THF as the mobile phase. NMR measurements were performed using Varian XL-3000, CFT-80 or EM-360 spectrometers with $\mathrm{CDCl}_{3}$ as solvent and TMS as internal standard. Infrared spectra were recorded on a Nicolet 10-DX FT-IR using $\mathrm{KBr}$ pellets. Preparative HPLC separations were done on a Waters 500 instrument equipped with two $500 \mathrm{~g}$ silica columns.

Synthesis of cis-trans-1,4-Diacetoxycyclohex2-ene

The synthesis of 1,4-diacetoxycyclohex-2ene is the first step to the synthesis of 2cyclohexen-1,4-diol using a procedure described by Rosenthal. ${ }^{16}$

A mixture of $32 \mathrm{~g}(0.39 \mathrm{~mol})$ of cyclohexene, $72 \mathrm{~g}(1.2 \mathrm{~mol})$ of acetic acid and $0.8 \mathrm{~g}$ of cuprous chloride was heated to $80-85^{\circ} \mathrm{C}$ while stirring. Then, $100 \mathrm{~g}$ of $70 \%$ tertiary butyl hydroperoxide $(0.78 \mathrm{~mol})$ was slowly added and the reaction mixture heated to $80^{\circ} \mathrm{C}$ for 16 hours. After cooling to room temperature, the solution was diluted with hexane and washed with distilled water. The organic phase was dried $\left(\mathrm{MgSO}_{4}\right)$ and evaporated prior to distillation at $10 \mathrm{mmHg}$ pressure. The 3,6-diacetoxycyclohexene boiling at $113-117^{\circ} \mathrm{C}$ was obtained in a $30 \%$ yield $(23.5 \mathrm{~g})$ together with $19.3 \mathrm{~g}(35 \%)$ of by-product 3-acetoxycyclohexene, recovered at $58-67^{\circ} \mathrm{C}$. The desired 1,4-diacetoxycyclohex-2-ene was obtained as a yellow liquid and shows the following spectroscopic and elemental analyses.

Anal. (C, H): Calcd C, $60.59 \%$; H, $7.12 \%$. Found C, 60.43\%; H, 7.07\%.

H NMR (39): $\delta 5.93$ (broad, $0.7 \mathrm{H}, \mathrm{CH}$ alkene, cis isomer); 5.91 (singlet, $1.3 \mathrm{H}, \mathrm{CH}$ alkene, trans isomer); $5.32(\mathrm{~m}, 1.3 \mathrm{H}, \mathrm{CH}-\mathrm{O}$, trans isomer); $5.24(\mathrm{~m}, 0.7 \mathrm{H}, \mathrm{CH}-\mathrm{O}$, cis isomer); $2.12\left(\mathrm{~m}, 1.3 \mathrm{H}, \mathrm{CH}_{\mathrm{e}}-\mathrm{CH}_{\mathrm{e}}\right.$, trans isomer); $2.08\left(\mathrm{~s}, 2.1 \mathrm{H}, \mathrm{CH}_{3}\right.$, cis isomer); $2.06(\mathrm{~s}, 3.9 \mathrm{H}$,
$\mathrm{CH}_{3}$, trans isomer); $1.88\left(\mathrm{~m}, 1.4 \mathrm{H}, \mathrm{CH}_{2}\right.$, cis isomer); and $1.70 \mathrm{ppm}\left(\mathrm{m}, 1.3 \mathrm{H}, \mathrm{CH}_{\mathrm{a}}-\mathrm{CH}_{\mathrm{a}}\right.$, trans isomer). ${ }^{1} \mathrm{H}$ NMR also shows that the ratio of the cis:trans diastereoisomers is $35: 65$.

${ }^{13}$ C NMR: $\delta 170.54(\mathrm{~s}) ; 130.27$ (d); 67.57 and 67.25 (2d); 25.74 and $24.82(2 \mathrm{t}) ; 21.20 \mathrm{ppm}(\mathrm{q})$.

IR: $1735(\mathrm{C}=\mathrm{O}) ; 1459\left(\mathrm{CH}_{2}\right.$ scissoring); $1454\left(\mathrm{CH}_{3}\right.$ asym. bending $) ; 1372\left(\mathrm{CH}_{3}\right.$ sym. bending); 1234 (C-O-C); and $791 \mathrm{~cm}^{-1}$ ( = C-H out-of-plane bend).

MS: absent $\left(\mathrm{M}^{+}\right) ; 139 \quad(\mathrm{vw}$, loss of $\mathrm{CH}_{3} \mathrm{COO}$ ); 96 (vs, loss of $\mathrm{CH}_{3} \mathrm{COO}$ and $\left.\mathrm{CH}_{3} \mathrm{CO}\right) ; 79$ (w, $\left.\mathrm{C}_{6} \mathrm{H}_{5}+2 \mathrm{H}\right) ; 78\left(\mathrm{w}, \mathrm{C}_{6} \mathrm{H}_{6}\right) ; 77$ (w, $\mathrm{C}_{6} \mathrm{H}_{5}{ }^{+}$); 43 (vs, $\mathrm{CH}_{3} \mathrm{CO}$ ).

\section{Synthesis of cis-trans-2-Cyclohexen-1,4-diol VIII a}

The 1,4-diacetoxycyclohex-2-ene, $\quad(18.0 \mathrm{~g}$, $91 \mathrm{mmol}$ ) was stirred for 3 days at room temperature with $11.0 \mathrm{~g} \mathrm{KOH}$ in $100 \mathrm{~g}$ of ethanol. The ethanol was evaporated and the brown residue washed in a soxhlet with ether. After most of the organic solvent was removed, the residue was distilled. The fraction collected at $130-132^{\circ} \mathrm{C}$ and $10 \mathrm{mmHg}$ yielded $6.2 \mathrm{~g}(60 \%)$ of the desired diol. Upon standing for a few days the viscous transparent product $^{17}$ became semi-solid. NMR analysis shows that the ratio of the cis:trans diastereoisomers is $45: 55$.

Anal. (C, H): Calcd C, 63.14\%; H, 8.83\%. Found C, 63.15\%; H, 8.88\%.

${ }^{1} \mathrm{H}$ NMR (39): $\delta 5.86$ (s, $0.9 \mathrm{H}, \mathrm{CH}$ alkene, cis isomer); $5.81(\mathrm{~s}, 1.1 \mathrm{H}, \mathrm{CH}$ alkene, trans isomer); $4.23(\mathrm{~m}, 1.1 \mathrm{H}, \mathrm{CH}-\mathrm{O}$, trans isomer); $2.11\left(\mathrm{~m}, 1.1 \mathrm{H}, \mathrm{CH}_{\mathrm{e}}-\mathrm{CH}_{\mathrm{e}}\right.$, trans isomer); 4.13 (m, $0.9 \mathrm{H}, \mathrm{CH}-\mathrm{O}$, cis isomer); $1.47(\mathrm{~m}, 1.1 \mathrm{H}$, $\mathrm{CH}_{\mathrm{a}}-\mathrm{CH}_{\mathrm{a}}$, trans isomer); $1.78\left(\mathrm{~m}, 1.8 \mathrm{H}, \mathrm{CH}_{2}\right.$, cis isomer), and $1.64 \mathrm{ppm}$ (broad singlet, $2 \mathrm{H}$, $\mathrm{OH})$.

${ }^{13} \mathrm{C}$ NMR: $\delta$ (in dioxan with external lock) 132.78 and $132.43(2 \mathrm{~d}) ; 66.42$ and $65.45(2 \mathrm{~d})$; 29.90 and $27.70 \mathrm{ppm}(2 \mathrm{t})$.

IR (neat): 3320 (H-bonding, OH); 1450 $\left(\mathrm{CH}_{2}\right.$ scissoring); $1062(\mathrm{C}-\mathrm{O}$ stretch $)$; and 
$742 \mathrm{~cm}^{-1}$ ( = C-H out-of-plane bend).

MS: $114\left(\mathrm{vw}, \mathrm{M}^{+}\right) ; 113(\mathrm{w}$, loss of $\mathrm{H}) ; 96(\mathrm{~m}$, loss of $\mathrm{H}_{2} \mathrm{O}$ ); 86 (w, loss of $\mathrm{C}_{2} \mathrm{H}_{4}$ ); 78 (w, loss of $2 \mathrm{H}_{2} \mathrm{O}$ ); 70 (vs, loss of $\mathrm{C}_{2} \mathrm{H}_{4} \mathrm{O}$ ); 57 (loss of $\mathrm{C}_{3} \mathrm{H}_{5} \mathrm{O}$ ).

Synthesis of Bis-p-nitrophenylcarbonate of 2Cyclohexen-1,4-diol, VIIIc

A solution of $31.82 \mathrm{~g}(158 \mathrm{mmol})$ of $p$ nitrophenyl chloroformate in $100 \mathrm{ml}$ of dry $\mathrm{CH}_{2} \mathrm{Cl}_{2}$ was added dropwise, over a period of $1 \mathrm{~h}$, into a solution of $9.01 \mathrm{~g}(79 \mathrm{mmol})$ of 2cyclohexen-1,4-diol and $12.48 \mathrm{~g}(158 \mathrm{mmol})$ of pyridine in $70 \mathrm{ml}$ of $\mathrm{CH}_{2} \mathrm{Cl}_{2}$. A suspension appeared and was allowed to reflux gently overnight. The product in suspension was brought into solution by adding more $\mathrm{CH}_{2} \mathrm{Cl}_{2}$. The solution was washed with distilled water, twice with $5 \% \mathrm{HCl}$ solution and again with water until neutral. The organic layer was dried over $\mathrm{MgSO}_{4}$, filtered and evaporated. The crude material was recrystallized from a $\mathrm{CH}_{2} \mathrm{Cl}_{2}$-petroleum ether mixture. After drying in vacuo, $21.05 \mathrm{~g}(61 \%)$ of the desired compound was recovered. Integration of the ${ }^{1} \mathrm{H}$ NMR shows a cis : trans ratio of $10: 90$ for the diol units.

Anal. (C, H, N): Calcd C, $54.06 \%$; H, 3.63\%; $\mathrm{N}, 6.30 \%$. Found C, $53.95 \%$;, $3.68 \%$, N, $6.21 \%$.

${ }^{1} \mathrm{H}$ NMR: $\delta 8.29(\mathrm{~d}, 4 \mathrm{H}) ; 7.40(\mathrm{~d}, 4 \mathrm{H}) ; 6.17$ $(\mathrm{m}, 2 \mathrm{H}) ; 5.34(\mathrm{~m}, 2 \mathrm{H}) ; 2.32\left(\mathrm{~m}, 1.8 \mathrm{H}, \mathrm{CH}_{\mathrm{e}}-\right.$ $\mathrm{CH}_{\mathrm{e}}$, trans isomer); $2.08\left(\mathrm{~m}, 0.4 \mathrm{H}, \mathrm{CH}_{2}\right.$, cis isomer); and $1.98 \mathrm{ppm}\left(\mathrm{m}, 1.8 \mathrm{H}, \mathrm{CH}_{\mathrm{a}}-\mathrm{CH}_{\mathrm{a}}\right.$, trans isomer).

${ }^{13} \mathrm{C}$ NMR: 155.35 (s); 151.96 (s, C=O); 145.39 (s); 129.93 (d); 125.29 (d); 121.68 (d); 72.13 (d); and $24.93 \mathrm{ppm}(\mathrm{t})$.

IR: 1754 (vs, $\mathrm{C}=\mathrm{O}) ; 1521$ and $1346\left(\mathrm{~s}, \mathrm{NO}_{2}\right.$ sym. and asym. stretch); 1256, 1214 (s, C-O-C stretch); $861 \mathrm{~cm}^{-\mathrm{r}}$ (m, =C-H out-of-plane bend).

MS: $\mathrm{M}^{+}$(absent); $262\left(\mathrm{w}\right.$, loss of $\mathrm{CO}_{2}$ and nitrophenyl radical); 218 (w, loss of $2 \mathrm{CO}_{2}$ and nitrophenyl radical); 217 (w, loss of $2 \mathrm{CO}_{2}$ and nitrophenol); 139 (m, nitrophenol); 80 (m, loss of $2 \mathrm{CO}_{2}$ and 2 nitrophenyl radicals); 79 (vs, loss of $2 \mathrm{CO}_{2}$, nitrophenyl radical and nitrophenol); 78 (m, loss of $2 \mathrm{CO}_{2}$ and 2 nitrophenols); $44\left(\mathrm{~m}, \mathrm{CO}_{2}\right)$.

\section{Preparation of the Diimidazolide IIIb}

A solution of $32 \mathrm{~g}$ of 1,1'-(1,4-phenylene)diethanol in $130 \mathrm{ml}$ dry THF was treated with $0.9 \mathrm{~g}$ of potassium metal and refluxed until the metal completely dissolved. After cooling, the solution was added to $62.3 \mathrm{~g}$ of 1,1'-carbonyldiimidazole in $80 \mathrm{ml}$ THF under argon. After $2 \mathrm{~h}$ at reflux the solvent was evaporated and the residue was purified by preparative HPLC to afford $39.4 \mathrm{~g}$ ( $58 \%$ yield) of the desired product, IIIb.

Anal. (C, H, N): Calcd C, $61.01 \%$; H, 5.12\%; $\mathrm{N}, 15.81 \%$. Found C, $60.76 \%$; H $5.17 \%$; , $15.61 \%$.

${ }^{13}$ C NMR: $\delta 147.95$ (s); 140.28 (s); 137.06 (d); $130.66(d) ; 126.71$ (d); 117.09 (d); 76.71 (d); and $21.87 \mathrm{ppm}(\mathrm{q})$.

${ }^{1} \mathrm{H}$ NMR: $\delta 8.04,7.30,6.96(\mathrm{~m}, 6 \mathrm{H}$, imidazol.); $7.36(\mathrm{~s}, 4 \mathrm{H}) ; 6.00$ (q, 2H); and $1.70 \mathrm{ppm}$ $(\mathrm{s}, 6 \mathrm{H})$.

IR $\left(\mathrm{cm}^{-1}\right)$ : $1748(\mathrm{C}=\mathrm{O}) ; 1634(\mathrm{C}=\mathrm{C}) ; 1525$ $(\mathrm{C}=\mathrm{N}) ; 1456\left(\mathrm{CH}_{3}\right.$ asym $) ; 1291,1263,1172$, 1097, 1064, and $1001(\mathrm{C}-\mathrm{O}-C, C-\mathrm{N}=\mathrm{C}$, and $\mathrm{N}-\mathrm{C}-\mathrm{C}$ str. $)$ and $837 \mathrm{~cm}^{-1}(=\mathrm{C}-\mathrm{H})$.

MS ( $m / e$; chem. ionization): $355(\mathrm{M}+1)$, 311, 267, 243, 199, 149, 131.

Similar procedures were used in the preparation of other bis-carbonylimidazolides. For example, VIIb prepared from sobrerol was obtained in $60 \%$ yield. Analysis of VIIb affords the following results:

Anal. (C, H, N): Calcd C, $60.32 \%, \mathrm{H}, 6.19 \%$; $\mathrm{N}, 15.63 \%$. Found C, $60.14 \% ; \mathrm{H}, 6.04 \%$; $15.63 \%$.

${ }^{1} \mathrm{H}$ NMR: $\delta 8.18(\mathrm{~s}, 1 \mathrm{H}) ; 8.03(\mathrm{~s}, 1 \mathrm{H}) ; 7.46$ (s, 1H); $7.27(\mathrm{~s}, 1 \mathrm{H}) ; 7.10(\mathrm{~s}, 1 \mathrm{H}) ; 7.03(\mathrm{~s}, 1 \mathrm{H})$; $5.86(\mathrm{~m}, 1 \mathrm{H}) ; 5.45$ (broad s, $1 \mathrm{H}) ; 1.78(\mathrm{~s}, 3 \mathrm{H})$; 1.58 and $1.62(2 \mathrm{~s}, 6 \mathrm{H}) ; 1.62$ to $2.56 \mathrm{ppm}(\mathrm{m}$, $5 \mathrm{H})$.

${ }^{13}$ C NMR: $\delta 148.37(\mathrm{C}=\mathrm{O}) ; 146.62(\mathrm{C}=\mathrm{O})$; $136.92(d) ; 136.64(d) ; 103.54$ and $130.30(2 d)$; 
$129.68(\mathrm{~s}) ; 128.71(\mathrm{~d}) ; 116.93$ and $116.69(2 \mathrm{~d})$; 88.90 (s); 75.26 (d); 37.49 (d); 29.61 (t); 26.55 (t); 20.41 (q); 22.94 and 23.33 ppm (2q).

IR: 1769 and $1755(\mathrm{C}=\mathrm{O}) ; 1618$ and 1480 $(\mathrm{C}=\mathrm{C}) ; 1529(\mathrm{C}=\mathrm{N})$; $1454\left(\mathrm{CH}_{2}\right.$ scissoring $)$; 1378 and $1390\left(\mathrm{CH}_{3}\right.$ gem-dimethyl); 1293, 1253, 1222, 1184, 1174, 1127, 1091, 1063 and 1003 (C-O-C, C-N-C, and N-C-C stretch); and $851 \mathrm{~cm}^{-1}$ ( $=\mathrm{C}-\mathrm{H}$ out-of-plane bending).

MS ( $m / e$, chemical ionization): 359 (vw, $\mathrm{M}+1) ; 315$ (vw, loss of $\mathrm{CO}_{2}$ ); 204 (w, loss of $2 \mathrm{CO}_{2}$ and imidazoyl radical); 203 (vs, loss of $2 \mathrm{CO}_{2}$ and imidazole); 137 (vw, loss of $2 \mathrm{CO}_{2}$ and 2 imidazoyl radicals); 135 ( $\mathrm{m}$, loss of $2 \mathrm{CO}_{2}$ and 2 imidazoles).

\section{Preparation of the Bis-p-nitrophenylcarbonate of p-Menth-6-ene-2,8-diol: VIIc}

A solution of $36.3 \mathrm{~g}$ of $p$-nitrophenyl chlo-

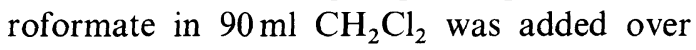
$25 \mathrm{~min}$ to a solution of $15.3 \mathrm{~g} p$-menth-6-ene2,8-diol in $200 \mathrm{ml} \mathrm{CH}_{2} \mathrm{Cl}_{2}$ containing $14.2 \mathrm{~g}$ dry pyridine. After $4 \mathrm{~h}$ at reflux the solution was cooled to room temperature, diluted with $180 \mathrm{ml} \mathrm{CH}_{2} \mathrm{Cl}_{2}$ and washed once with $120 \mathrm{ml}$ water then twice with $100 \mathrm{ml} 5 \% \mathrm{HCl}$ and finally with water unit neutral. After drying $\left(\mathrm{MgSO}_{4}\right)$ the solvent was evaporated and the product was recrystallized from $\mathrm{CH}_{2} \mathrm{Cl}_{2}-$ petroleum ether to afford $32 \mathrm{~g}(71 \%)$ of pure VIIc.

Anal. (C, H, N): Calcd C, 57.60\%; H, 4.83\%; $\mathrm{N}, 5.60 \%$. Found C, 57.82\%; H, 4.93\%; N, $5.75 \%$.

${ }^{1} \mathrm{H}$ NMR: $\delta 8.23$ and $8.21(2 \mathrm{~d}, 4 \mathrm{H}) ; 7.32$ and $7.36(2 \mathrm{~d}, 4 \mathrm{H}) ; 5.78(\mathrm{~m}, 1 \mathrm{H}) ; 5.18$ (broad s, $1 \mathrm{H})$; 1.56 to $2.37(\mathrm{~m}, 5 \mathrm{H}) ; 1.76(\mathrm{~s}, 3 \mathrm{H}) ; 1.52$ and $1.54 \mathrm{ppm}(2 \mathrm{~s}, 6 \mathrm{H})$.

${ }^{13} \mathrm{C}$ NMR: $\delta 155.53(\mathrm{~s}) ; 152.27(\mathrm{~s}, \mathrm{C}=\mathrm{O})$; $150.36(\mathrm{~s}, \mathrm{C}=\mathrm{O}) ; 145.24$ (s); 129.67 (s, C alkene); 128.64 (d, CH alkene); 125.14 (d); 121.84 and $121.61(2 \mathrm{~d}) ; 87.97$ (s); 76.69 (d); $37.44(\mathrm{~d}) ; 29.33(\mathrm{t}) ; 26.46$ (t); 20.59 (q); 22.63 and $23.17 \mathrm{ppm}(2 \mathrm{q})$.

IR: 1765 and $1749(\mathrm{C}=\mathrm{O}) ; 1614$ and 1492 $(\mathrm{C}=\mathrm{C}$ stretch $) ; 1515$ and $1348\left(\mathrm{NO}_{2}\right) ; 1458$
$\left(\mathrm{CH}_{2}\right.$ scissoring); 1374 and $1382\left(\mathrm{CH}_{3}\right.$ gemdimethyl); 1259, 1221, 1162, 1133 and 1110 (C-O-C); 858 (=C-H out-of-plane), $848 \mathrm{~cm}^{-1}$ ( =C-H out-of-plane bend).

MS: absent $\left(\mathrm{M}^{+}\right) ; 318\left(\mathrm{w}\right.$, loss of $\mathrm{CO}_{2}$ and nitrophenyl radical); 317 (w, loss $\mathrm{CO}_{2}$ and nitrophenol); 274 (w, loss of $2 \mathrm{CO}_{2}$ and nitrophenyl radical); $273\left(\mathrm{w}\right.$, loss $2 \mathrm{CO}_{2}$ and nitrophenol); 136 (w, loss of $2 \mathrm{CO}_{2}$ and 2 nitrophenyl radicals); 135 ( $\mathrm{m}$, loss of $2 \mathrm{CO}_{2}$ nitrophenyl radical and nitrophenol); 134 (w, loss of $2 \mathrm{CO}_{2}$ and 2 nitrophenols); 139 (m, nitrophenol); 107 (vs, loss of $2 \mathrm{CO}_{2}, 2 \mathrm{CH}_{3}$, nitrophenol and nitrophenyl radical).

Similar procedures are used in the preparation of other bis- $p$-nitrophenylcarbonates. For example, bis(4-nitrophenyl)2-cyclohexen-1,4ylene dicarbonate (VIIIc) is obtained in $61 \%$ yield. ${ }^{14}$

\section{Preparation of Polymer XI by Reaction of $\mathrm{Vb}$ with IIIa}

A solution of $20.0000 \mathrm{~g}(59.85 \mathrm{mmol})$ of $\mathrm{Vb}$ in $20 \mathrm{ml} \mathrm{CH} \mathrm{Cl}_{2}$ was treated with $9.9482 \mathrm{~g}$ $(59.85 \mathrm{mmol})$ or diol IIIa, $2.0 \mathrm{~g}$ of 18 -crown-6, and $10 \mathrm{~g}$ powdered anhydrous potassium carbonate. The mixture was stirred overnight at $65^{\circ} \mathrm{C}$ though monomer disappearance was almost complete within $2-3 \mathrm{~h}$. The reaction mixture was diluted with $\mathrm{CH}_{2} \mathrm{Cl}_{2}$ and filtered after centrifugation and decantation. The solution was then concentrated and the polymer precipitated twice in methanol to yield $15.41 \mathrm{~g}$ $(71 \%)$ of XI. Analysis confirms that the polymer is a regularly alternating copolycarbonate of 2,5-dimethyl-2,5-hexanediol and 1,1'-(1,4-phenylene)-diethanol (see Table I).

Anal. (C, H): Calcd C, $65.91 \%$; H, 7.74\%. Found C, 66.19\%; H, 7.98\%.

${ }^{1} \mathrm{H}$ NMR: $\delta 1.39(\mathrm{~s}, 12 \mathrm{H}) ; 1.50(\mathrm{~d}, 6 \mathrm{H}) ; 1.72$ (m, 4H); $5.53(\mathrm{~g}, 2 \mathrm{H})$; and $7.26 \mathrm{ppm}(\mathrm{s}, 2 \mathrm{H})$.

${ }^{13} \mathrm{C}$ NMR: $\delta 22.35$ (q); 25.90, 25.70 (q); 34.01 (p); 75.04 (d); 83.64 (s); 126.14 (d); $141.26(\mathrm{~s})$; and $152.68 \mathrm{ppm}(\mathrm{s}, \mathrm{C}=\mathrm{O})$.

IR $\left(\mathrm{cm}^{-1}\right)$ : $1739(\mathrm{C}=\mathrm{O}) ; 1515(\mathrm{C}=\mathrm{C}) ; 1488$ $\left(\mathrm{CH}_{2}\right.$, scissoring); $1453\left(\mathrm{CH}_{3}\right) ; 1393$ and 1372 
(dimethyl); 1260, 1206, 1162, 1082 (C-O-C); 859 and $839(=\mathrm{C}-\mathrm{H})$; and $793 \mathrm{~cm}^{-1}(\mathrm{C}=\mathrm{C})$.

MW: $\bar{M}_{n}=10,300$ (osmometry); GPC: $\bar{M}_{n}=$ 17,$800 ; \bar{M}_{w}=30,700 ; D=1.7$.

Preparation of Polymer XV from IIb and VIIIa

A mixture of $0.22755 \mathrm{~g}(1.9936 \mathrm{mmol})$ of the diol, VIIIa, $0.65053 \mathrm{~g}(1.9936 \mathrm{mmol})$ of the biscarbonylimidazolide IIb, $0.1 \mathrm{~g}$ of 18 -crown-6, $2 \mathrm{~g}$ of anhydrous potassium carbonate, and $3 \mathrm{ml}$ of dry dichloromethane was prepared under argon atmosphere. This reaction mixture was stirred and refluxed for $45 \mathrm{~h}$. After the usual work-up, the material was precipitated in methanol and $0.34 \mathrm{~g}(56 \%$ yield $)$ of a white polymer is recovered. This polymer was shown to consist of chains of low molecular weight of the desired polycarbonate, XV.

IR: 3475 (O-H stretch, terminal hydroxyls); $1741(\mathrm{C}=\mathrm{O}) ; 1454\left(\mathrm{CH}_{2}\right.$ scissoring); 1242, 1196 and $1079(\mathrm{C}-\mathrm{O}-\mathrm{C})$; and $792 \mathrm{~cm}^{-1}$ ( = C-H out-of-plane bend).

MW (GPC): $\bar{M}_{n}=2,800, \bar{M}_{w}=3,900, D=$ 1.4 .

Preparation of Polymer XV from IIc and VIIIa

A mixture of $1.13478 \mathrm{~g}(9.9542 \mathrm{mmol})$ of the diol VIIIa, $4.66225 \mathrm{~g}(9.9542 \mathrm{mmol})$ of the bisp-nitrophenyl carbonate IIc, $0.63 \mathrm{~g}$ of 18 crown- $6,7 \mathrm{~g}$ of anhydrous $\mathrm{K}_{2} \mathrm{CO}_{3}$, and $15 \mathrm{ml}$ of dry $\mathrm{CH}_{2} \mathrm{Cl}_{2}$ was stirred and refluxed for $90 \mathrm{~h}$ under argon. After work-up and three precipitations into 1.5 liter of methanol $2.76 \mathrm{~g}$ (91\% yield) of the pure white polymer was obtained. The cis : trans ratio of the cyclohexenediol in the polymer is shown to be $35: 65$ by ${ }^{1} \mathrm{H}$ NMR.

Anal. (C, H): Calcd C, $63.12 \%$; H, 5.30\%. Found C, 63.36\%; H, 5.49\%.

${ }^{1} \mathrm{H}$ NMR: $\delta 7.36(\mathrm{~s}, 4 \mathrm{H}) ; 5.96(\mathrm{~m}, 2 \mathrm{H}) ; 5.14$ (m, 6H); $2.15(\mathrm{~m}, 1.3 \mathrm{H}$, trans $), 1.92(\mathrm{~m}, 1.4 \mathrm{H}$, cis $)$, and $1.76 \mathrm{ppm}(\mathrm{m}, 1.3 \mathrm{H}$, trans $)$.

${ }^{13} \mathrm{C}$ NMR: $\delta 154.51 \quad(\mathrm{C}=\mathrm{O}) ; 135.47$ (s); 129.97 (d); 128.51 (d); 71.09 (d); 69.41 (t); 25.25 (t, trans); and $24.57 \mathrm{ppm}(\mathrm{t}$, cis $)$.

IR: $1742(\mathrm{C}=\mathrm{O}) ; 1452\left(\mathrm{CH}_{2}\right.$ scissoring);
1244, 1196, and $1079(\mathrm{C}-\mathrm{O}-\mathrm{C})$; and $792 \mathrm{~cm}^{-1}$ ( = C-H out-of-plane bend).

DSC: $T_{\mathrm{g}}=65^{\circ} \mathrm{C} ; 3$ endotherms at 73,87 , and $123^{\circ} \mathrm{C}$.

MW (Osmom.): $\bar{M}_{n}=17,600 ;$ GPC: $\bar{M}_{n}=$ $7900, \bar{M}_{w}=15,000, D=1.9$.

\section{Preparation of Polymer XVI by Reaction of VIIIc with VIa}

This polymer was prepared in $90 \%$ yield by a procedure ${ }^{14}$ similar to that used for 15 .

\section{Preparation of Polymer XVIII by Reaction of VIIc with IIa}

A mixture of $12.2073 \mathrm{~g}(24.392 \mathrm{mmol})$ of compound VIIc, $3.3703 \mathrm{~g}(24.392 \mathrm{mmol})$ of the diol, $1.5 \mathrm{~g}$ of 18 -crown- $6,20 \mathrm{~g}$ of anhydrous potassium carbonate and $50 \mathrm{ml}$ of dry dichloromethane was prepared under argon atmosphere. This reaction mixture was stirred at reflux for $41 \mathrm{~h}$ until all of the starting materials were consumed. After cooling to room temperature, the mixture was worked-up by diluting with $\mathrm{CH}_{2} \mathrm{Cl}_{2}$ and centrifuging the suspension. The decanted solution was then concentrated on rotatory evaporator and precipitated four times into 3 litre of methanol. After drying in vacuo, $7.08 \mathrm{~g}(81 \%)$ of a white polymer is recovered.

Anal. (C, H): Calcd C, 66.65\%; H, 6.71\%. Found C, 66.79\%; H, 6.99\%.

${ }^{1} \mathrm{H}$ NMR: $\delta 7.28(\mathrm{~m}, 4 \mathrm{H}) ; 5.62($ broad s, $1 \mathrm{H}$, alkene); $5.03(\mathrm{~m}, 5 \mathrm{H}) ; 1.64(\mathrm{~s}, 3 \mathrm{H}) ; 1.48$ to 2.11 (s, $5 \mathrm{H}) ; 1.38$ and $1.42 \mathrm{ppm}(2 \mathrm{~s}, 6 \mathrm{H})$.

${ }^{13} \mathrm{C}$ NMR: $\delta 155.04(\mathrm{~s}, \mathrm{C}=\mathrm{O}) ; 153.28(\mathrm{~s}$, $\mathrm{C}=\mathrm{O}) ; 135.78$ and 135.65 (2s); 130.05 (s); 128.28 and $128.16(2 \mathrm{~d}) ; 128.05(\mathrm{~d}) ; 85.36(\mathrm{~s})$; 75.01 (d); $68.92(\mathrm{t}) ; 68.25$ (t); 37.69 (d); 29.54 (5); 26.19 (t); 20.58 (q); 23.06 and 23.25 ppm (2q).

IR: $1740(\mathrm{C}=\mathrm{O}) ; 1452\left(\mathrm{CH}_{2}\right.$ scissoring); $1379\left(\mathrm{CH}_{3}\right.$ sym. bending), 1265, 1247, 1211, $1160,1136,1084$, and 1025 (C-O-C stretch); 847 (=C-H out-of-plane bending); and $790 \mathrm{~cm}^{-1}$ ( = C-H out-of-plane).

MW (Osmom.): $\bar{M}_{m}=11100$; GPC: $\bar{M}_{n}=$ 
$6100, \bar{M}_{w}=10000, D=1.6$.

DSC: $T_{\mathrm{g}}=111^{\circ} \mathrm{C}$.

Preparation of Polymer XIX from VIIc and VIa

A suspension of $5.00461 \mathrm{~g}(0.01000 \mathrm{~mol})$ of bis-p-nitrophenyl carbonate IIIc, $2.28294 \mathrm{~g}$ $(0.01000 \mathrm{~mol})$ of bispherol $\mathrm{A}, 0.68 \mathrm{~g}$ of $18-$ crown-6, $6.8 \mathrm{~g}$ of potassium carbonate and $20 \mathrm{ml}$ of dry $\mathrm{CH}_{2} \mathrm{Cl}_{2}$ was prepared under argon atmosphere. This preparation was stirred at refluxed for $48 \mathrm{~h}$ until all starting materials were consumed. After the usual dilution and centrifugation, the decanted solution was concentrated and precipitated three times into 41 of methanol in order to remove all of the p-nitrophenol. After drying in vacuo, $3.56 \mathrm{~g}$ $(79 \%)$ of XIX was recovered as a white powder.

Anal. (C, H): Calcd C, 71.98\%; H, 6.71\%. Found C, $72.07 \%$; H, 6.79\%.

${ }^{1} \mathrm{H}$ NMR: $\delta 7.14(\mathrm{~m}, 4 \mathrm{H}) ; 7.00(\mathrm{~m}, 4 \mathrm{H}) ; 5.72$ $(\mathrm{m}, 1 \mathrm{H}) ; 5.14(\mathrm{~m}, 1 \mathrm{H}) ; 1.76(\mathrm{~s}, 3 \mathrm{H}) ; 1.60(\mathrm{~m}$, $6 \mathrm{H}) ; 1.53$ and 1.51 (2s, 3H each); $1.65-2.28$ ppm $(\mathrm{m}, 5 \mathrm{H})$.

${ }^{13}$ C NMR: $\delta 153.74(\mathrm{C}=\mathrm{O}) ; 151.90(\mathrm{C}=\mathrm{O})$; 148.95 (s); 147.78 (s); 129.99 (s); 128.30 (d); 127.75 and 127.70 (d); 120.64 and 120.37 (d); 86.45 (s); 75.68 (d); 42.41 (s); 37.81 (d); 30.90 (q); $29.52(\mathrm{t}) ; 26.34(\mathrm{t}) ; 23.06$ and $22.96(\mathrm{q})$; $20.65 \mathrm{ppm}(\mathrm{q})$.

IR: 1758 (vs, $\mathrm{C}=\mathrm{O}$ ); 1600 and 1508 (w and $\mathrm{m}, \mathrm{C}=\mathrm{C}$ arom.); 1249, 1215, 1128 (vs, C-O-C stretch); and $835 \mathrm{~cm}^{-1}(\mathrm{~m},=\mathrm{C}-\mathrm{H}$, out-ofplane bending arom.).

MW (Osmom.): $\bar{M}_{n}=15400 ;$ GPC: $\bar{M}_{n}=$ $15300, \bar{M}_{w}=32200, D=2.1$.

DSC: $T_{\mathrm{g}}=130^{\circ} \mathrm{C}$.

\section{Imaging Experiments}

An example of imaging is given below for polymer XIX, other polymers are imaged in somewhat similar fashion. Details of electronbeam imaging experiments will be given elsewhere.

A solution is prepared from $1.08 \mathrm{~g}$ of polymer XIX and $0.106 \mathrm{~g}$ of triphenylsulfonium hexafluoroantimonate in $8 \mathrm{~g}$ methyl cellosolve acetate. The solution was spin-coated on $125 \mathrm{~mm}$ silicon wafers washed in $\mathrm{HF}$ and the wafers were pre-baked at $80^{\circ} \mathrm{C}$ for $5-15 \mathrm{~min}$. Exposure was carried out through a test mask using a Perkin-Elmer deep-UV projection printing tool operating at scan speed 20004000. Other wafers exposed at lower scan speeds (360 or 1000) are underexposed. Upon post-baking of the wafers at $80^{\circ} \mathrm{C}$ a visible positive image appears immediately but this image is only incompletely developed as some of the material which is produced by the catalyzed thermolysis reaction is not very volatile at the post-bake temperature under atmospheric pressure. Full development was achieved by brief immersion or spraying of the exposed wafers in isopropanol followed by drying under a stream of nitrogen.

Figures 15 and 16 show scanning micrographs of positive images obtained from polymers XVI and XIX by the process described above.

Acknowledgements. Financial support of this research by the Natural Sciences and Engineering Research Council of Canada (NSERC) and by IBM Corporation is gratefully acknowledged. Fellowship support from NSERC for F.B. and T.I. is also acknowledged with thanks.

\section{REFERENCES}

1. C. G. Willson, "Introduction to Microlithography," L. F. Thompson, C. G. Willson, and M. J. Bowden, Ed., ACS Symposium Series, No. 219, 1983, p 144.

2. T. Hirai, Y. Hatano, and S. Nonogaki, $J$. Electrochem. Soc., 118, 659 (1986).

3. H. Shiraishi, Y. Taniguchi, S. Horigomi, and S. Nonagaki, Polym. Eng. Sci., 20, 1058 (1980).

4. H. S. Choong and F. J. Kahn, J. Vac. Sci. Technol., 19, 1121 (1981); S. Imamura, T. Tamamura, K. Harada, and S. Sugawara, J. Appl. Polym. Sci., 27, 937 (1982); Y. Tabata, S. Tagawa, and M. Washio, "Materials for Microlithography," L. F. Thompson, C. G. Willson, and J. M. J. Fréchet, Ed., ACS Symposium Series, No. 266, 1984, p 151.

5. C. G. Willson, H. Ito, M. J. Fréchet, T. G. Tessier, 
and F. M. Houlihan, J. Electrochem. Soc., 133, 181 (1986).

6. H. Ito, C. G. Willson, and J. M. Fréchet, Microcircuit Eng., 262 (1982); H. Ito and C. G. Willson, "Polymers for Microelectrics," T. Davidson, Ed., ACS Symposium Series, No. 242, 1984, p 11.

7. J. M. J. Fréchet, F. Bouchard, F. M. Houlihan, B. Kryczka, E. Eichler, N. Clecak, and C. G. Willson, J. Imaging Sci., 30, 59 (1986).

8. J. M. J. Fréchet, F. M. Houlihan, F. Bouchard, B. Kryczka, and C. G. Willson, J. Chem. Soc., Chem. Commun., 1514 (1985).

9. F. M. Houlihan, F. Bouchard, J. M. J. Fréchet, and C. G. Willson, Macromolecules, 19, 13 (1986).

10. R. Taylor, "Chemistry of Carboxylic Acids and Derivatives Supplement," No. 2, S. Patoi, Ed., John Wiley \& Sons, New York, N. Y., 1979, p 860.

11. J. V. Crivello and J. H. W. Lam, J. Polym. Sci.,
Polym. Chem. Ed., 17, 977 (1979).

12. M. Bodanszky, "Principles of Peptide Synthesis," Springer-Verlag, New York, N. Y., 1984.

13. F. M. Houlihan, J. M. J. Fréchet, and C. G. Willson, Polym. Mater. Sci. Eng., 53, 268 (1985).

14. J. M. J. Fréchet, F. Bouchard, F. M. Houlihan, E. Eichler, B. Kryczka, and C. G. Willson, Makromol. Chem., Rapid. Commun., 7, 121 (1986).

15. S. C. Narang and A. T. Attarwala, Polym. Prepr., Am. Chem. Soc., Div. Polym. Chem., 26, 323 (1985).

16. R. Rosenthal (Atlantic Richfield Company), US Patent 3,953,526 (1974).

17. J. E. Baäckvall, S. E. Bystroöm, and R. E. Nordberg, J. Org. Chem., 49, 4628 (1984).

18. B. C. Clark, C. C. Powell, and T. Radford, Tetrahedron, 33, 2189 (1977).

19. F. M. Houlihan, B. Kryczka, and J. M. J. Fréchet, manuscript in preparation. 